\title{
Controlling superconductivity by light
}

\author{
Ron Naaman \\ NPG Asia Materials (2015) 7, e175; doi:10.1038/am.2015.26; published online 17 April 2015
}

In the growing field of nanotechnology, there is an interest in developing hybrid organic-inorganic devices that have controllable electrical or magnetic properties. ${ }^{1}$ Because of the nanoscale involved, the surface-to-volume ratio in these devices is large; hence, the devices can be controlled by varying their surface properties. Exerting control by using light is particularly attractive because making conventional hard electric contacts may be difficult due to size and material properties. The work of Suda et al. ${ }^{2}$ presents a device in which superconductivity is controlled by light through the excitation of a gate made from spiropyran. ${ }^{3}$ Figure 1 schematically presents the device and its mode of operation (right panel) relative to that of a common field effect transistor (left panel). Spiropyran serves as the gate and is reversibly photoisomerized from a nonionic to a zwitterionic form. In its neutral form, no field is applied to the thin single crystal of $\kappa$-(BEDT-TTF) ${ }_{2} \mathrm{Cu}\left[\mathrm{N}(\mathrm{CN})_{2}\right] \mathrm{Br}(\kappa-\mathrm{Br})$ (BEDT-TTF: bis(ethylenedithio)tetrathiafulvalene). Upon photoexcitation with UV light, zwitterions are formed in the spiropyran film, and as a result, holes are injected into the $\mathrm{\kappa}-\mathrm{Br}$, converting it to a superconductor at low temperatures. Irradiation with visible light returns the film to its neutral state.

This work presents several interesting new concepts. The ability to observe the photo-induced
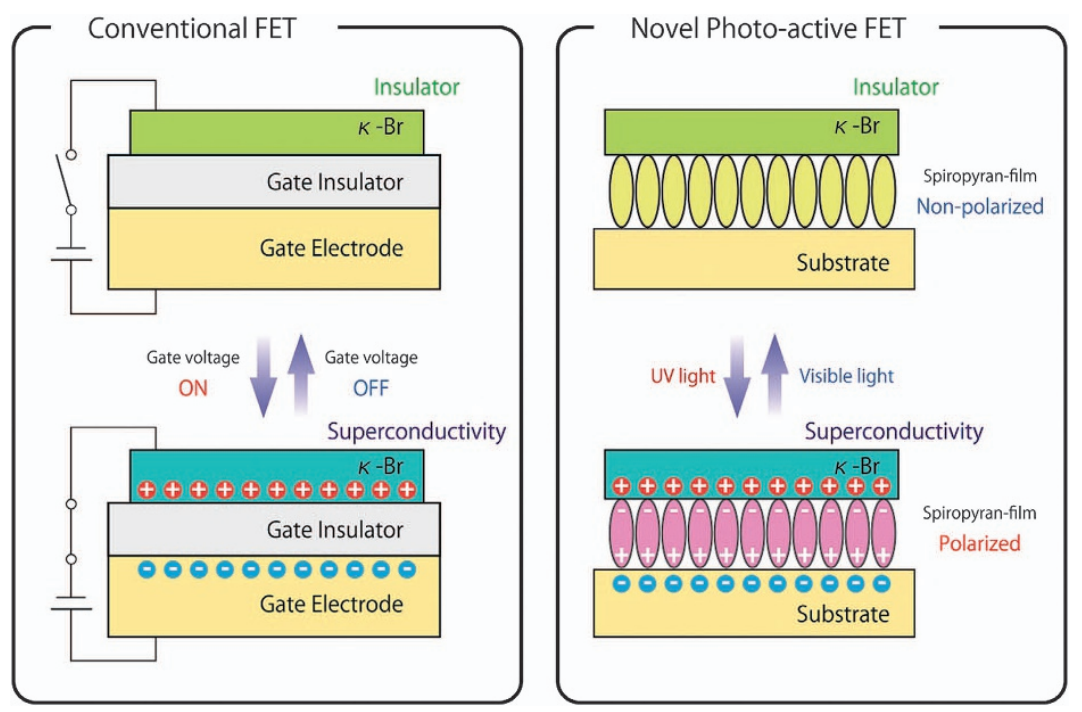

Figure $1 \mathrm{~A}$ schematic that illustrates (on the right) the new photo-activated field effect transistor (FET)like structure that transforms the $\mathrm{\kappa}$ - $\mathrm{Br}$ active layer into a superconductor by the photoisomerization of a spiropyran film that serves as a light-activated gate. A common FET is shown on the left.

transition to a superconducting state at low temperature is related to the special properties of spiropyran, in which photoisomerization occurs even at low temperatures. The electric double layer that forms as a result of the photoisomerization generates an enormous electric field, which is difficult to achieve using common gate materials. This effect is due to the proximity of the gate layer to the electrically active $\mathrm{\kappa}-\mathrm{Br}$. The field transforms $\kappa-\mathrm{Br}$ from a Mott insulator into a superconductor by doping it with holes. This work demonstrates the importance of controlling interfaces in order to determine the electric and magnetic properties of nanostructures. ${ }^{4}$
1 Zhu, L., Zhu, M.-Q., Hurst, J. K. \& Li, A. D. Q. Lightcontrolled molecular switches modulate nanocrystal fluorescence. J. Am. Chem. Soc. 127, 8968-8970 (2005).

2 Suda, M., Kato, R. \& Yamamoto, H. M. Light-induced superconductivity using a photoactive electric double layer. Science 347, 743-746 (2015).

3 Guglielmetti, R. in: Photochromism: Molecules and Systems (eds Durr H., Bouas-Laurent H.) 314 (Elsevier, Amsterdam, 1990).

4 Naaman, R. Molecular controlled nano-devices. Phys. Chem. Chem. Phys. 13, 3153 (2011).

(c) (i) This work is licensed under a Creative Commons Attribution 4.0 International License. The images or other third party material in this article are included in the article's Creative Commons license, unless indicated otherwise in the credit line; if the material is not included under the Creative Commons license, users will need to obtain permission from the license holder to reproduce the material. To view a copy of this license, visit http:// creativecommons.org/licenses/by/4.0/ 